\title{
CÂNCER E O SUJEITO EM PSICOTERAPIA: HORIZONTES DE TRABALHO NA PERSPECTIVA EXISTENCIALista de JEAN-PAul Sartre
}

\author{
Fabiola Langaro* \\ Zuleica Pretto** \\ Bruna Germano Cirelli***
}

\section{Resumo}

Este artigo apresenta o relato de um processo psicoterápico realizado com Sofia, uma mulher de 36 anos em tratamento médico para um câncer de mama. Com base na teoria existencialista de Jean-Paul Sartre, compreendeu-se a doença como geradora de mudanças significativas em seu projeto de ser pelas alteraçóes provocadas em suas relaçóes e, consequentemente, em sua experiência de ser quem é. A partir disto, o objetivo principal do processo foi viabilizar Sofia a partir das diferentes condiçốes e horizontes existenciais impostos pela doença, sem esquecer que experiências de sofrimento a atingiram em toda sua história e complexidade e não somente aquelas circunscritas à ocorrência do câncer. Finalizado o processo psicoterápico, considera-se que foi possível reorganizar seu projeto de ser, na medida em que se possibilitou a ela compreender aspectos importantes da trajetória que havia percorrido e ainda de suas possibilidades concretas no presente e para seu futuro.

Palavras-chave: câncer; psicologia clínica; Jean-Paul Sartre; existencialismo.

\section{Abstract \\ CANCER AND THE SUBJECT IN PSYCHOTHERAPY: WORK HORIZONS FROM THE Jean-Paul Sartre existentialist perspective}

This article presents a report of a psychotherapy process conducted with Sofia, a woman of 36 years old, carrying through a medical treatment for breast cancer. Based on the existentialist

* Centro Hospitalar Unimed Joinville/SC e Associação Catarinense de Ensino/Faculdade Guilherme Guimbala, Joinville/SC, Brasil. E-mail: flangaro@hotmail.com

** Departamento de Psicologia, Universidade do Sul do Estado, Palhoça/SC, Brasil. E-mail: zuleicapretto@yahoo.com.br.

*** Domus - Centro de Terapia de Casal e Família, Porto Alegre/RS, Brasil. E-mail: borboleta_bruna@hotmail.com. 
theory of Jean-Paul Sartre, the cancer was considered as provoking significant changes in her being project, mainly caused by changes in her relationships and, consequently, in her experience of being who she was. From this, the main objective of the process was feasible Sofia from different horizons and existential conditions imposed by the disease, without forgetting that reached the experiences of suffering in all its history and complexity, and not only limited to the occurrence of cancer. Finished the psychotherapeutic process, it is considered that it was possible to rearrange Sofia being project, as it enabled her to understand important aspects of the path she had trod and yet her specific possibilities in the present and her future.

Keywords: cancer; clinical psychology; Jean-Paul Sartre; existentialism.

Este artigo apresenta o relato de um processo psicoterapêutico ocorrido no contexto de uma Clínica de Atenção Integral à Saúde, vinculado a uma Unidade Básica de Saúde e ao Sistema Único de Saúde (SUS), por um período de 12 meses. Trata-se de uma mulher, Sofia ${ }^{1}$, de 36 anos, em tratamento médico para um câncer de mama.

Descreve-se, neste trabalho, a experiência vivida por Sofia e como sua situação de vida foi compreendida e trabalhada na psicoterapia a partir da teoria existencialista sartriana em psicologia. Para isso, conceitos como escolha, projeto-de-ser, complicaçóes psicológicas, adoecimento, morte, corpo e emoçóes, bem como o método fenomenológico e dialético proposto por essa teoria, foram norteadores na compreensão e na intervenção psicoterapêuticas. Salienta-se também que o conhecimento sobre a doença orgânica, o tratamento do câncer oferecido pela medicina, em especial na rede pública de saúde brasileira, e a discussão de autores contemporâneos que se debruçam sobre a temática do adoecimento por meio do câncer foram igualmente essenciais.

Desse modo, o artigo retrata alguns aspectos centrais do trabalho clínico realizado com Sofia, num esforço de apresentar uma história “já realizada”. Destaca-se que um texto não abarca a totalidade das múltiplas facetas, as contradições e a riqueza dos movimentos dialéticos ocorridos no processo psicoterapêutico, já que o movimento vivido de um sujeito é complexo e dinâmico, assim como o seu processo de psicoterapia. Porém percebe-se a relevância desse esforço na medida em que, como destaca Silva (2009), é necessário um maior número de pesquisas e publicações que retratem trabalhos com as experiências das pessoas que são acometidas pelo câncer a partir delas mesmas e não de teorias gerais que, comumente, tentam indicar a maneira "correta" de viver esse processo, universalizando as experiências.

Importante ressaltar que um cuidado adotado no decorrer dos atendimentos de Sofia foi o de não reduzi-la a ser uma mulher com câncer. Isto é, por mais 
que o câncer se colocasse como central em suas experiências, transpassando suas relaçóes, estava diante da psicoterapeuta uma mulher em sua totalidade de ser, mãe, amiga, filha, amante, profissional, com uma história de vida, com conflitos anteriores e atuais, sendo o câncer e o seu tratamento elementos que se articulavam e ganhavam sentido a partir dessa mesma história.

Nesse sentido, no caso de Sofia, considerou-se que a experiência do câncer envolveu diversos aspectos. Um deles foi o de assumir a doença como uma nova dimensão de seu ser-no-mundo, o que exigia apropriação de elementos dessa nova realidade, como a rotina de tratamentos, a incerteza da cura, a possibilidade da morte, as mudanças no seu corpo, as dores físicas. Outros aspectos implicaram a revisão da rede de apoio social para ela e a filha, relacionamentos com familiares, condiçôes de trabalho, o adiamento ou mudanças de planos futuros e em consequência uma ruptura em seu projeto de ser constituído até então, como será discutido adiante. Dessa maneira, a doença pode ser compreendida como geradora de mudanças significativas em seu projeto-de-ser, tendo em vista que alterou a experiência vivida e, com ela, suas açóes, estados e, finalmente, qualidades de seu ser. Não se buscou, portanto, um agente causador para o aparecimento do câncer de Sofia, uma vez que a doença envolve uma diversidade de variáveis que se articulam de modo complexo.

Assim, serão apresentados brevemente saberes relacionados ao câncer na contemporaneidade e como essa condição foi vivenciada por Sofia; a constituição do sujeito em Sartre, ressaltando a relação desta com o corpo, uma vez que o sofrimento de Sofia, naquele momento, estava fortemente relacionado a um acontecimento que abateu diretamente seu corpo; o câncer e o tratamento; e, por fim, a descrição sucinta dos principais aspectos trabalhados no processo psicoterapêutico propriamente dito e seus desdobramentos na história de vida de Sofia.

Em termos metodológicos esta produção se caracteriza como um estudo de caso elaborado com base nos relatos dos atendimentos psicológicos realizados com Sofia. Este delineamento, segundo Chizzotti (2003), possibilita estudar um fenômeno particular ao longo de um processo e deve contar com registros que permitam a análise teórica e a proposta de ações interventivas.

\section{O câncer na contemporaneidade}

Apesar dos avanços da oncologia, o câncer é considerado uma das doenças de maior fatalidade na contemporaneidade, um problema de saúde pública, associado à dor e à morte, a procedimentos cirúrgicos deformadores e tratamentos 
violentos e dolorosos. Segundo dados do Instituto Nacional do Câncer (INCA, 2009), este se configura como uma importante causa de doença e morte no Brasil, visto que, desde 2003, as neoplasias malignas constituem a segunda causa de morte na populaçáo, representando aproximadamente $17 \%$ dos óbitos de causa conhecida.

Neste cenário, de acordo com Neme e Lipp (2010), os cânceres de mama estão entre as primeiras causas de mortalidade entre as mulheres e, somados aos cânceres de ovários e de útero, levam à morte milhares de mulheres por ano no Brasil e no mundo. As autoras destacam ainda que grande número de pesquisas indica o impacto das doenças oncológicas femininas nos diversos aspectos da vida das mulheres e que, quanto mais grave a condição da mulher com câncer, "maiores são as perdas físicas, psicológicas e os riscos de comorbidades, gerando dificuldades crescentes para o enfrentamento da doença, dos tratamentos e das mudanças sociais, econômicas e de rotina de vida individual e familiar" (Neme \& Lipp, 2010, p. 476).

Também Peres e Santos (2009) evidenciam que as taxas de incidência do câncer de mama aumentam anualmente, sobretudo como reflexo da tendência global à predominância de estilos de vida que fomentam a exposição a fatores de risco. Por essa razão, o controle deste câncer se destaca como uma preocupação crescente para os serviços nacionais de saúde pública. Em seu estudo, os autores observaram que a assistência psicológica a mulheres portadoras desta doença tornou-se um assunto recorrente na literatura especializada.

Os principais tratamentos para o câncer são a quimioterapia e a radioterapia. Comumente, a rotina imposta por elas tem efeitos colaterais acentuados, fragilizando ainda mais a pessoa, que já está sendo afetada em todas as dimensões de sua existência: orgânica, psicológica, social, estética, cultural, econômica. Há também um agravo em relação a prognósticos, uma vez posta a possibilidade de metástases ou a impossibilidade de cura (Silva, 2009).

Sontag (2007) descreve que o câncer na contemporaneidade é visto como ameaçador e mortal. Contribuem para esta visão características atribuídas a ele como: ser uma doença que pode surgir inesperadamente, de crescimento às vezes visível, predominantemente interno; ter evolução anormal e finalmente letal, com desenvolvimento descompassado, incessante e firme; destruir a vitalidade; embotar o desejo sexual; transformar o ato de comer em suplício - náuseas e falta de apetite; acarretar perda de peso, pois o canceroso é invadido por células que o consomem; eventualmente tratar-se do estágio final da vida; uma vez instalado não depender do ambiente físico - é uma luta dentro do próprio corpo; atingir parte do corpo cujo reconhecimento é embaraçoso (bexiga, reto, cólon, 
seio, próstata, testículo); ser mórbido, trazer uma morte horrível, medo, agonia; revelar que o corpo é apenas o corpo; ter como principais metáforas indicaçóes topográficas - o câncer "se espalha ou prolifera", "se difunde".

Outra reflexão importante realizada por Sontag (2007) é relativa a avaliações psicológicas que tendem a buscar nas características psicológicas do sujeito causas para o aparecimento do câncer. A autora argumenta que este pode ser um poderoso meio de colocar a culpa no doente uma vez que, por um lado, instala a lógica da punição, pois é, sobretudo, vergonha que se atribui a uma doença considerada consequência da repressão da emoçáo ou falta de expressividade, fruto de uma personalidade fracassada. Por outro lado, isenta outras variáveis causadoras da doença, como as condiçóes socioeconômicas, por exemplo, repetindo, assim, o erro de polarizar a doença em apenas um aspecto: se antes o biológico, agora o psicológico.

Finalmente, vale salientar que cada paciente reage de forma particular ao processo de adoecer. Isto ocorre a partir de uma diversidade de variáveis que caracterizam cada história de vida, tais como características orgânicas, tipo de câncer, idade, história de vida familiar, social, cultural e econômica, relação que aprendeu a manter com a morte e com a dor nas experiências de outras pessoas que teve oportunidade de acompanhar, possibilidades de acesso a serviços de saúde, qualidade do atendimento pelos profissionais de saúde, entre outros aspectos.

\section{A constituiçáo do sujeito em Sartre e a doença como modificadora do projeto-de- ser}

Sartre descreve em O existencialismo é um humanismo (Sartre, 1945/1978a) que o homem é um ser-no-mundo, o que significa que é dotado de um corpo e de uma consciência através dos quais se relaciona com o mundo, estabelecendo relaçôes que caracterizam sua existência.

Um corpo que o lança num tempo e num espaço, isto é, numa situação existencial específica e que, unificado a uma consciência (definida como nada, voltada ao que é exterior a ela, como relaçáo ou intencionalidade), oferece as possibilidades de o sujeito se relacionar com o mundo, ver o outro, ser visto pelo outro e, com isso, inserir-se e ser inserido num movimento concreto de constituição de si, do outro e da história coletiva. É por meio desta condição psicofísica, ontológica, que o sujeito estabelece relação com dada realidade antropológica e poderá, entâo, constituir sua singularidade como totalidade em que o psicológico será "encarnado" no corpo e o corpo vivido como psicológico. 
Esta concepção teórica pressupõe, assim, "que o homem primeiramente existe, se descobre, surge no mundo; e que só depois se define. [...] O homem não é mais do que o que ele faz" (Sartre, 1945/1978a, p. 12). Assim, não há, para o existencialismo sartriano, natureza humana, visto que o homem não pode ser definido antes que seja concebido e, por isso, não se poderá achar em cada homem uma essência universal. O que existe é uma condição humana, que compreende "mais ou menos distintamente o conjunto de limites a priori que esboçam a sua situação fundamental no universo” (Sartre, 1945/1978a, p. 16).

Para Sartre, no sentido ontológico a liberdade é definidora do ser da realidade humana, pois "[...] é precisamente o nada que é tendo sido no âmago do homem e obriga a realidade-humana a fazer-se em vez de ser" (Sartre, 1943/1997, p. 545). Condenado à liberdade (Sartre, 1945/1978a), o sujeito será obrigado a fazer escolhas na realidade antropológica e sociológica em que estiver inserido, o que faz com que só possa ser compreendido levando-se em consideração sua história individual implicada por um contexto. É no estabelecimento das relações com o outro, que irão mediar suas relaçóes com as coisas, com o tempo e com seu próprio corpo, que o sujeito terá possibilidades de construir sua personalidade. Portanto, o tecido sociológico implica em uma rede de relaçóes de mediaçóes (Schneider, 2006) que fornece os parâmetros para a construção da singularidade do sujeito, resultando em sua dimensão psicológica.

Nessa direção, os sujeitos constituem-se a partir de suas escolhas e açóes que estấo sempre relacionadas a um projeto, um desejo de ser. Suas escolhas cotidianas relacionam-se a uma escolha fundamental que os leva a um projeto-de-ser fundamental, caracterizado pela totalização de açóes em curso que é o homem. Sendo este projeto movido por um desejo de ser, podemos pensar que é principalmente a partir deste desejo - especificado em diferentes desejos concretos - que move o homem e que o orienta no estabelecimento de suas relaçóes no mundo.

A ação humana, portanto, está sempre direcionada ao futuro, para aquilo que o indivíduo ainda não é, pois “[...] o homem, antes de mais nada, é o que se lança para um futuro, e o que é consciente de se projetar no futuro. $\mathrm{O}$ homem é, antes de mais nada, um projeto que se vive subjetivamente [...]" (Sartre, 1945/1978a, p. 12). Descreve Sartre (1943/1997) que o futuro, ao mesmo tempo que aparece no horizonte para anunciar ao sujeito o que ele é a partir do que ainda será, também caracteriza o sujeito em sua possibilidade de não ser este futuro, visto que "o Futuro não é, o Futuro se possibiliza (possibilise). Futuro é a contínua possibilidade (possibilisation) dos Possíveis como sentido do Para-si presente" (Sartre, 1943/1997, p. 183).

Assim, considerando que toda ação do homem o leva ao futuro e ao seu projeto, tem-se que, ao mover-se no mundo, o sujeito poderá se deparar com di- 
ficuldades que podem inviabilizá-lo no seu desejo de ser ou, ainda, que provocam uma ruptura no projeto-de-ser até então constituído. Entre estas rupturas está o surgimento de uma doença como o câncer, que se interpóe ao projeto de vida de um sujeito.

Conforme destaca Silva (2009, p. 63), a experiência de sentirem-se lançados no mundo para cumprir uma parte de sua existência com o câncer "é vivida como uma experiência aniquiladora, desestruturadora do seu projeto existencial por um ente que náo esperavam encontrar pelo caminho". A doença se instala como algo que pretere as escolhas do sujeito e que irrompe apesar de seus esforços. Ao mesmo tempo, ela o impele a fazer escolhas a partir do diagnóstico, impondo-lhe uma reorganização de seu projeto em todas as dimensóes: orgânicas, sociais, amorosas, profissionais, familiares.

Esta nova condição de ser no mundo poderá impor ao sujeito uma reformulação do significado que tiver dado à sua existência. Neste sentido, para lutar por sua permanência enquanto ser no mundo terá que se apropriar da condição de portador de um câncer e reformular seu projeto a partir desta nova experiência de ser. Segundo descreve Silva,

não há como abrir mão da facticidade de estar no mundo com câncer, a não ser que se escolha o não-ser, pelo suicídio, por exemplo. Mas, para continuar sendo no mundo, há que se acordar do sonho e tomar providências. $\mathrm{O}$ acordar implica em saber-se angustiado diante da possibilidade do não-ser, porém também requer a decisão de escolher a possibilidade de ser-no-mundo-com câncer (Silva, 2009, p. 64).

Se uma reformulação de projeto-de-ser que ocorra a partir de uma escolha crítica do sujeito implica em revisóes de suas dinâmicas-de-ser, de sua história de relaçóes e de sua constituição enquanto ser-no-mundo, o que muitas vezes é experienciado de forma dolorosa e cambaleante, uma reorganização do projeto a partir de uma ruptura inesperada, imperativa e complexa como o surgimento de um câncer pode ser uma experiência ainda mais complexa. Isto porque:

o assumir-se enquanto ser-no-mundo-com-câncer não isenta o caminho escolhido de dificuldades. As coisas não se tornam mais fáceis pelo fato de o projeto existencial ter sido retomado. Ele foi retomado numa perspectiva náo esperada, muito menos desejada. Acolher e investir no projeto de uma existência com câncer é colocar-se em estado de fragilidade, sujeito a carências, incertezas (Silva, 2009, p. 65). 
Assim, as alterações no contexto ontológico, sociológico e antropológico na vida de um sujeito provocam alteraçôes em suas perspectivas psicológicas. Isso ocorre porque o sujeito se objetiva e se apropria dos arranjos com os quais convive, subjetivando-se neles/por eles, sendo justamente nessas condiçóes que se constitui a experiência de ser quem é, que o orienta em seu movimento no mundo e que resulta em determinada dinâmica-de-ser ou dinâmica psicológica (Schneider, 2006).

Nesta perspectiva, a psicoterapia com base no Existencialismo tem como proposta mediar o sujeito na construçáo de ferramentas que lhe possibilitem alterar e superar as situaçóes difíceis e de sofrimento. Para tal, faz uso de uma metodologia específica, fenomenológica e dialética que, em linhas gerais, concentra-se em momentos de investigações, compreensões e intervenções ao longo de um processo dinâmico em que o psicoterapeuta é essencialmente um mediador e o sujeito deve ser essencialmente ativo, protagonista. O uso de técnicas interventivas deve ser sempre condizente com as particularidades dos casos em questão (Aguiar, 2007; Maheirie \& Pretto, 2007; Pretto, Langaro \& Bunn Santos, 2009; Sartre 1943/1997, 1960/1978b; Schneider, 2008, 2011). Antes de apresentar o trajeto de Sofia no processo psicoterápico a ser discutido neste artigo, porém, cabem ainda reflexóes sobre uma das principais relaçóes que se alteram a partir da experiência do câncer: a do sujeito com seu corpo.

\section{O meu corpo e os outros}

A relação do sujeito com seu corpo é a mediação essencial da relação do sujeito com os objetos na medida em que é a conexão entre o si mesmo e o mundo. Neste sentido, a percepção do próprio corpo é um pôr-se em um lugar, em um tempo, com limites e possibilidades demarcados, em que "o corpo representa a individualização de meu comprometimento no mundo" (Sartre, 1943/1997, p. 393).

Há para Sartre (1943/1997) três dimensóes ontológicas do corpo: o corpo como ser-para-si; o corpo como ser-para-o-outro; e o corpo enquanto experiência do sujeito sendo conhecido pelo outro em funçáo do seu corpo, ou seja, de existir para si "como conhecido por outro a título de corpo" (Sartre, 1943/1997, p. 441).

Assim, o corpo enquanto ser-para-si é a própria experiência do corpo, ou seja, do corpo concreto, por meio do qual o sujeito se relaciona, pré-reflexivamente, com o mundo. Ele é, assim, o centro de referência indicado pela exterioridade, sendo não somente "a sede dos cinco sentidos", mas também o instrumento e a meta das açôes dos sujeitos, presente em toda a ação, como corpo vivido. Além disso, pela 
constituição psicofísica do ser, o corpo é o possibilitador da consciência, na medida em que é a relação originária do sujeito com a materialidade (Sartre, 1943/1997).

Aprofundando a discussão do corpo enquanto ser-para-si, Van Den Berg (1994) descreve que "falar do seu próprio corpo significa falar de si mesmo", na medida em que é com o corpo que somos, que nos relacionamos em nossas atividades cotidianas. Assim, "uma pessoa lava-se, não é o seu corpo que se lava. Uma pessoa barbeia-se, não é o seu rosto que se barbeia. E se está barbeando o seu queixo, não está barbeando o queixo da face que tem, mas da face que é" (Van Den Berg, 1994, p. 47).

Conforme o mesmo autor, uma perturbação - incluindo uma doença aninha-se no corpo que somos, para então fazer surgir outra forma de relação com o corpo, o corpo que temos - ou corpo como ser-para-o-outro, visto que poderá ser entáo tomado como objeto pelo outro e por mim mesmo. Assim descreve Van Den Berg (1994, p. 46): "ao dizer que tem um corpo, a gente se retira, de certo modo, da vida de todos os dias. Dizendo isso, modificamos um pouco nosso corpo, pois o corpo que temos é diferente do corpo que somos".

Desta forma, pré-reflexivamente, o corpo é vivido como o corpo que somos, mas, táo logo a reflexão estabeleça alguma distância entre o sujeito e o seu próprio corpo, este passa a ser um corpo enquanto objeto pertencente à materialidade e passível de ser dissecado, estudado e entendido, "ao passo que aquilo que somos não pode ser dissecado” (Van Den Berg, 1994, p. 47). Na experiência da doença, portanto, o que o médico descreve sobre o corpo do paciente pode náo fazer sentido para este, uma vez que se refere a corpos "diferentes".

A experiência do corpo como ser-para-o-outro remete, de acordo com Sartre (1943/1997, p. 427), à "relação fundamental entre meu ser e o ser do outro", sendo que "o corpo do outro é sua facticidade como utensílio e como síntese de órgãos sensíveis, na medida em que ela se revela à minha facticidade. É dada a mim desde que o outro existe para mim no mundo" (Sartre, 1943/1997, p. 430). Assim, o corpo do outro aparece secundariamente na relaçáo do sujeito com o outro, na medida em que o outro primeiro existe, para depois ser capturado e conhecido como corpo. Além disso, o corpo do outro é "a facticidade da transcendência-transcendida" (Sartre, 1943/1997, p. 432), visto que é um para-si que se lança sempre para além do que está dado, ainda que possa ser capturado enquanto objeto, mas não é possível ao sujeito captar o corpo do outro sem captar, ao mesmo tempo, seu corpo "como centro de referência indicado pelo outro" (Sartre, 1943/1997, p. 432).

Finalmente, a terceira dimensão ontológica do corpo, "enquanto sou Para-outro, o outro se desvela a mim como o sujeito para o qual sou objeto" (Sartre, 1943/1997, p. 441). Assim, pelo olhar do outro, o sujeito sente-se apreendido em 
sua própria facticidade, sendo alcançado em sua existência de fato. É a experiência do corpo alienado, visto que o sujeito sente-se objeto em poder do outro. Além disso,

a experiência de minha alienação faz-se em e por estruturas afetivas, como
a timidez. "Sentir-se enrubescer", "sentir-se transpirando", etc. são expres-
sões impróprias que o tímido usa para explicar seu estado: o que ele quer
dizer com isso é que tem consciência viva e constante de seu corpo tal
como é náo para si mesmo, mas para o outro (Sartre, 1943/1997, p. 443).

Estas três dimensôes do corpo precisam ser compreendidas e descritas pela psicologia em todos os casos clínicos, na medida em que revelam náo somente a relação do sujeito com seu corpo, mas também aquilo que o caracteriza enquanto ser, visto que "a existência do outro revela-me o ser que sou" (Sartre, 1943/1997, p. 453). Apesar disso, quando o sujeito experimenta o adoecimento do corpo enquanto estrutura orgânica, torna-se ainda mais imperativa a compreensão da relação que o sujeito estabelece com seu corpo e, por meio dele e da consciência, com o outro.

Neste sentido, é possível pensar que, na medida em que o sujeito é também um corpo permeado e transpassado pela relação entre o eu e o outro, entre o eu e a exterioridade, se este corpo se altera, alteram-se as relaçóes com o corpo, com o outro e com o mundo. Se o corpo do sujeito é, assim, acometido por uma doença, por uma alteração fisiológica ou orgânica, a experiência do corpo como ser-em-si-mesmo se altera (cai o cabelo, mutila-se uma de suas partes, sentem-se náuseas, fraqueza, vômitos, há emagrecimento, perda de energia para a realização de atividades rotineiras, entre outros sintomas). Consequentemente, alteram-se as experiências de corpo como ser-para-o-outro e do "ser-aí-para-o-outro", tendo em vista que a experiência do corpo é um centro de referência organizador do existente.

Portanto, ao vivenciar uma alteraçáo no corpo, o sujeito experimenta uma alteração em seu ser psicofísico e, consequentemente, em seu movimento no mundo. Compreender esta alteraçáo implica conhecer a história do sujeito, sua dinâmica psicológica e a inteligibilidade que ele direcionou a estas novas ocorrências, experienciadas psicofisicamente.

\section{O processo psicoterápico de Sofia}

Sofia foi encaminhada à psicoterapia por fisioterapeutas que a atendiam em seu tratamento para o câncer, tendo em vista queixas de depressão pós-mastectomia. Nas entrevistas iniciais, apresentou-se uma mulher bonita, frequente- 
mente usando lenços coloridos na cabeça (estava careca em função da quimioterapia), maquiada e comunicativa. Além do acompanhamento psicológico e da fisioterapia, fazia quimioterapia em um centro de pesquisas oncológicas e um tratamento espiritual em um centro de apoio ao paciente com câncer. Revelou-se fragilizada pela doença, sentindo-se cansada. Sofia recebia auxílio-doença, estava afastada do trabalho como operadora de telemarketing, tendo relatado ser este um trabalho extremamente exaustivo e desgastante.

Havia descoberto o nódulo quando amamentava sua filha, Antonia. O diagnóstico foi de carcinoma profundo e em dois meses realizou a cirurgia para a remoção de um quadrante do seio e raspagem da axila com alguns linfonodos atingidos. Teve duas tias maternas que morreram devido ao câncer de mama, mas acreditava ter desenvolvido a doença a partir de intenso sofrimento vivido em função de relacionamentos amorosos conturbados e da gravidez e paternidade da filha, envolvidos nesses relacionamentos.

Sofia relatou que a gravidez da filha não foi planejada, foi fruto de um relacionamento breve com um estrangeiro, Mário, e logo em seguida com Júlio, que morava na mesma cidade que ela. Ao descrever o longo processo de desentendimentos com Júlio até a confirmação e assunção da paternidade de Mário, relatou ter sido esta a pior fase de sua vida. Na época, fez tratamento de dois anos e meio com um psiquiatra, fazendo uso de Fluoxetina e Rivotril. Após o início do tratamento do câncer, parou de usar a medicação devido à quimioterapia.

Natural de uma cidade do interior do estado, mudou-se para a cidade com dezenove anos em busca de independência. Destacou o fato de ser uma pessoa independente, prescindindo de auxílio de outros; segundo ela, morava sozinha, longe de toda a família (tinha treze irmãos); era mãe solteira, cuidava sozinha de Antônia, tinha dois empregos, estudava à noite, levava uma vida extremamente agitada, sem compromisso com outros além dela e da filha; ganhava seu dinheiro, sustentava a filha e tinha apartamento próprio. Porém estava deprimida, em especial por não conseguir se mostrar independente nas atuais circunstâncias.

Sentia-se culpada por dar pouca atenção à filha Antônia, de quatro anos. Comentou que outras crianças que residiam no mesmo prédio falaram para a filha que sua mãe estava morrendo, o que lhe acarretou atitudes de insegurança e dependência da mãe (medo de escuro, não queria desenhar sozinha, pedia que a mãe ficasse junto dela, pois do contrário dizia que não conseguiria fazer). Bastante comovida, chorando muito, confessou ter ameaçado sua filha falando "sem pensar" que a deixaria sozinha. Disse que sentia culpa pela sua atitude, porém não 
estava conseguindo lidar com a nova situação de vida; sentia culpa também pela impaciência com a filha e de ter atitudes impulsivas de briga, quando gritava e às vezes agredia Antônia fisicamente; preocupava-se por não saber dar-lhe limites, temendo pela sua educação.

Falava que sofria por saber que sua família estava preocupada com sua saúde; queixava-se da relação distante que mantinha com sua mãe, não conseguindo constituir com ela uma relação de afeto. Apesar de referir a fragilidade e cansaço com a doença e o tratamento, inicialmente não fazia referências diretas ao que a doença significava para ela, nem às possibilidades ou não de cura.

A partir das informaçóes obtidas nas entrevistas iniciais, compreendeu-se que, frente à doença grave e diante da "experiência de ser quem era" relacionada a alguém que era independente e que "daria conta de tudo", se deparava com uma nova realidade em que se experimentava frágil, sem autonomia. Sofia apresentava-se em conflito com sua condição de fragilidade, pretendendo realizar as mesmas atividades que executava anteriormente, o que provocava nela irritação, em especial com a filha, visto que era especialmente nesta relação que se deparava com sua própria exigência e também com suas impossibilidades em cumpri-la da forma como desejava. Porém seu organismo demonstrava cansaço e exigia repouso, imposiçóes físicas que a colocavam em contradição com sua anterior disposição e independência.

Para lidar com esta condição, às vezes fingia que nada estava acontecendo, se recusando a lançar mão de açóes condizentes com a realidade que se colocava como, por exemplo, pedir ajuda aos outros. Assim, continuava fazendo as atividades que fazia antes e não seguia o repouso recomendado pelos profissionais que a acompanhavam no tratamento.

Segundo Sartre (1939/2006), em algumas situações da história do sujeito o mundo pode se apresentar como difícil e imperativo, tendo em vista que o sujeito é requisitado a agir frente a uma realidade já determinada, não passível de mudança. Nessas ocasióes, como forma de lidar com a angústia gerada por esta condição, o sujeito altera a si mesmo, via processo da emoção, por exemplo, para sair desta condiçẫo de sofrimento que a necessidade de ação e de escolha lhe impõe.

Neste sentido, "a experiência de ser quem é” de Sofia, ou seja, a inteligibilidade que tinha sobre si mesma indicava a ela que era uma mulher forte e independente, que não se deixaria abater pelo câncer. A realidade, porém, se apresentava dura, dolorida, seu corpo fraquejava para além do seu controle, revelando o mundo determinado com o qual tinha dificuldades de lidar, que se apresentava inviabilizante de seu projeto-de-ser. 
Com essa compreensão psicoterapêutica, iniciou-se um processo de tornar evidente, para Sofia, sua dinâmica psicológica, demonstrando de que modo a doença havia modificado seu posicionamento em suas relaçóes. Os principais aspectos trabalhados a partir de entáo foram:

1. a relação com a doença e o tratamento - orientado para a construção de instrumentos que a auxiliassem a enfrentar as consequências da quimioterapia. Estas intervençôes visaram minimizar possíveis dificuldades decorrentes do tratamento e também a elaboração das mudanças por ele provocadas na experiência de ser de Sofia, em sua relação com o mundo, com seu corpo, com os outros, com a materialidade e com a própria possibilidade de morte;

2. a relação com a filha, incluindo o cuidado quando ela estivesse ausente, a qualidade dos momentos em que estavam juntas, o diálogo aberto, a forma de lidar com a insegurança e falta de limites da filha, a rede de apoio caso ela ficasse mal. Discutiu-se com ela a questão de que impaciência, falta de tempo e dificuldades na educação da filha já existiam antes da doença, o que apontava a necessidade de trabalhar a história de vida de Sofia. Este foi um ponto importante: nem tudo o que ela vivia estava condicionado pela sua condição de ser uma pessoa com câncer, apesar de ser evidente que sua condição física agravava ainda mais suas dificuldades na vivência de ser mãe, por exemplo provocando insegurança e medos;

3. as atitudes que ela gostaria de modificar com relação à sua mãe (já que admitiu sofrer com a distância afetiva que se mantinha entre as duas);

4. seus projetos de sua vida antes e depois do câncer (profissão, novos filhos, casamento, estilo de vida). Ressalta-se que estes últimos aspectos, porém, não serão detalhadamente explorados neste trabalho.

Schneider (2011) afirma que a psicologia clínica sartriana tem por objetivo evidenciar a personalidade do sujeito, investigando em que contexto o sujeito chegou a ser quem é, ou seja, quais as possibilidades que o levaram a constituir-se enquanto personalidade singular. Por meio dessa investigação podem-se analisar variáveis constituídas nas relaçóes concretas do sujeito, compreendendo o conjunto de fenômenos que contribuíram para o surgimento de eventuais complicaçôes psicológicas e de sofrimento.

No caso de Sofia, a psicoterapia teve como objetivo refletir conjuntamente acerca dessas questóes de forma crítica a partir de uma consciência posicional de 
si que torna o eu objeto de reflexão e, deste modo, buscou localizar a paciente em seu momento atual, revisando com ela os caminhos e escolhas feitas ao longo de sua história e clareando outras possibilidades de escolha. Ainda, a prática utilizada nas sessões, unindo conhecimentos da psicologia existencialista e conhecimentos da psico-oncologia - enquanto área de interface psicologia e a oncologia (Carvalho, 2002) pretendeu instrumentalizar a paciente em seu movimento no mundo frente às novas situaçóes e experiências geradas pelo câncer.

É possível compreender que uma doença como o câncer pode colocar o sujeito diante da proximidade de sua morte, uma possibilidade humana concreta, porém muitas vezes pouco considerada pelos sujeitos. Segundo Sartre (1943/1997, p. 657), quando a morte não está relacionada ao limite da velhice, mas "nos aniquila na maturidade ou na juventude [...] seria o mesmo que esperar com a ideia de que minha vida é uma empresa falida". Descreve Sartre (1943/1997, p. 658) que "esta perpétua aparição do acaso no âmago de meus projetos não pode ser captada como minha possibilidade, mas sim, ao contrário, como nadificação de todas as minhas possibilidades [a morte surge, então,] como uma nadificação sempre possível de meus possíveis".

Neste sentido, Sofia falava em psicoterapia sobre o sentimento de solidão, principalmente durante a noite, quando as suas incertezas com relação à sua cura a faziam chorar muito. Segundo Silva (2009, p. 84), "viver com câncer é experienciar a incerteza constante de que o tratamento pode não conter a doença. Os doentes manifestam um temor permanente de não serem curados, assim como de a doença evoluir para metástase. O projeto existencial é vivenciado sempre em suspensão".

Questionada sobre como era para ela este sentimento e se havia compartilhado estas dúvidas com alguém, afirmou que todos a estavam tratando como se ela estivesse ótima. Disse que, por vezes, se sentia "invisível”, parecendo que ninguém a enxergava do modo real, com câncer. Reforçou ainda que esses sentimentos de desamparo e solidão a acompanhavam há muito tempo, nas suas relaçóes com a mãe, nos seus relacionamentos amorosos. Falou que gostava do modo positivo como todos se relacionavam com ela, mas sabia, agora, que estava doente e gostaria de ter mais atençáo e cuidados dos outros. Isso evidenciava, por um lado, uma contradiçáo entre como se percebia e o modo como os outros a reconheciam e, por outro lado, entre sua experiência de ser anterior, "desprendida" dos outros, e a experiência atual, querendo este outro táo próximo dela.

Sofia chorou muito em uma das sessóes, quando disse que "agora caiu a minha ficha, e tudo o que eu queria era estar normal, saudável”. Havia recebido do médico a notícia sobre o início da quimioterapia com uma medicação um 
pouco mais forte, sendo alertada sobre a possibilidade de queda de todos os pelos de seu corpo, inclusive cílios. Sofia referiu estar apavorada diante destes agravos nas consequências do tratamento, sentir muito medo, pois havia pensado que nada poderia ser pior do que a reaçâo de sua última quimioterapia. Sobre este aspecto, Silva (2009, p. 71), descreve que "por causa dos efeitos colaterais o tratamento é vivenciado como um suplício, uma violência que provoca trauma, que lesiona não somente o físico, mas também a própria vontade de seguir adiante. Nessa condição a pessoa se fragiliza [...] Vivencia o esmaecimento, o desfalecimento, a solidão".

Sofia sentia-se fragilizada e muito fraca. Quando estava em casa sem o lenço na cabeça, procurava não passar em frente aos espelhos; quando se via não conseguia se reconhecer. Estava insegura com relação ao tratamento, momento em que foi enfatizada a importância do esclarecimento de suas dúvidas com os médicos. Segundo Silva (2009), para o paciente com câncer é fundamental o bom vínculo com os profissionais que o atendem,

\begin{abstract}
é importante para ele que os profissionais sejam claros e eficientes na comunicação. Caso contrário, o doente se vê imerso em dúvidas, adquire uma atitude receosa e desconfiada, sentimentos que lhe fazem pesar mais ainda o fardo com o qual tem de caminhar no novo espaço circunstanciado pela doença (Silva, 2009, pp. 76-77).
\end{abstract}

Estas reaçóes de Sofia frente ao tratamento contra o câncer relacionam-se ao que Sartre (1943/1997) descreve como a indicação que o corpo fornece das possibilidades do sujeito no mundo e, portanto, por meio das quais é possível a ocorrência de uma complicação psicológica, na medida em que o "meu corpo" passa a ter limitaçóes em relação ao mundo e na relação que faço do meu reconhecimento através do outro. Além disso, o adoecimento do corpo impóe ao sujeito uma possível iminência da morte, na medida em que deixa de ser "a morte" para torna-se "a minha morte". Neste sentido, descreve Sartre (1943/1997, p. 656) que, "precisamente, a possibilidade de minha morte significa apenas que não sou biologicamente senão um sistema relativamente fechado, relativamente isolado; assinala somente o pertencer de meu corpo à totalidade dos existentes".

Assim, o relato de Sofia era de que a semana que antecedia a quimioterapia era terrível, pois se sentia "como um carneiro indo para o abate", indicando que o tratamento, considerado benéfico para a sua saúde, era experimentado como algo que a agredia. Nesta perspectiva, experimentava seu corpo como "coisa" ou 
"objeto", ou seja, como um corpo para o outro, preso no olhar e na ação do outro e, portanto, alienado. Descreve Sartre (1943/1997, p. 442) que, "meu corpo, enquanto alienado, escapa-me rumo a um ser-ferramenta-entre-ferramentas, rumo a um ser-órgão-sensível-captado-por-órgãos-sensíveis, e isso com uma destruição alienadora e um desmoronamento concreto de meu mundo, que escoa rumo ao outro e que o outro irá retomar em seu mundo”.

Ao realizar o tratamento médico para o câncer, em que seu ser era reduzido ao seu "corpo doente", Sofia sentia-se como um "conjunto de órgãos", ou seja, como o corpo somente em sua dimensão do em-si, objeto passível de conhecimento e manejo do outro. Seu ser era reduzido ao corpo que necessitava de intervenção química, ficando ela vulnerável à ação do outro, excluindo-se a sua possibilidade de escolha e desejo. A palavra "paciente", neste caso, descreve efetivamente alguém a quem os médicos tratam como um ser passivo, a quem, muitas vezes, são omitidas informaçóes e a chance de ser ativo em seu processo de saúde/doença, aumentando ainda mais o sentimento de um corpo alienado pela ação do outro.

\section{Modificaçóes constatadas em psicoterapia}

Ao longo dos atendimentos, os efeitos colaterais da quimioterapia tornaram-se agressivos, os vômitos e as dores mais frequentes, e Sofia apresentava-se abatida, pálida e com olheiras profundas. Em meio a estes momentos de intenso sofrimento, porém, tomou atitudes que representavam novas totalizações acerca dos conteúdos trabalhados em psicoterapia, como ficou expresso nas seguintes situaçôes: no convite que fez ao irmão e aos amigos para acompanhá-la no tratamento; na constatação de que a escolha de esconder-se dos amigos, para não demonstrar que estava fraca, não a ajudava a enfrentar a realidade e a mantinha na solidão; na busca de esclarecimentos com os médicos sobre medicaçôes e prognósticos.

Sobre os cuidados com a filha, Sofia negociou horários de chegada e saída na escola nos dias em que tivesse médico e contratou uma pessoa para ficar com ela em sua ausência. Além disso, trabalhou a qualidade dos momentos na companhia da filha, propôs mais atividades e diálogo, o que fez com que se sentisse mais realizada e presente como mãe. Além disso, definiu o projeto de trabalhar somente meio período para que pudesse levar e buscar a filha na escola e almoçar com ela. Para alcançar este objetivo, estava fazendo o curso de gestão de pessoas, prevendo uma possibilidade de atuar na área como autônoma. Algumas semanas 
após estas definições, se ausentou da psicoterapia por uma semana, pois foi visitar a família no dia dos pais, investindo também na relação com eles. Ao retornar, sentia-se tranquila e feliz por estar terminando as sessóes de quimioterapia, ter visto os pais e todos os irmãos.

Nesse período realizou um tratamento alternativo, com o aval dos médicos do centro de pesquisas oncológicas, com medicamentos que aumentavam a imunidade e a produção de leucócitos e hematócitos. Porém este tratamento era caro, o que fez com que solicitasse auxílio financeiro ao pai de sua filha, que morava no exterior, o qual não se negou a fazê-lo.

Deu-se conta, através destas açôes, que era preciso expor suas dificuldades aos outros que, sem isso, não poderiam se disponibilizar a ajudá-la. Reconheceu, também, que escolhas por diferentes atitudes partiam de uma decisão sua e que dessa forma construía a sua história singular, promovendo consequências na resolução de suas complicaçóes psicológicas. Segundo Sartre (1960/1978b, p. 19), só há realidade na ação: "o homem [...] só existe na medida em que se realiza, não é, portanto, nada mais do que o conjunto dos seus atos, nada mais do que a sua vida". Além disso, compreende-se que "o homem define-se pelo seu projeto. Esse ser material supera perpetuamente a condição que lhe é dada; revela e determina sua situação, transcendendo-a para objetivar-se, pelo trabalho, pela ação ou pelo gesto" (Sartre, 1960/1978b, p. 177), o que lhe possibilita estar sempre lançado para certo futuro. Mesmo, às vezes, entristecendo-se frente à condição de doença grave, Sofia havia iniciado um processo de reformulaçáo de seu projeto-de-ser.

Os atendimentos seguintes evidenciaram uma mulher com mais energia; o tratamento médico apresentava bons resultados, os cabelos começaram a crescer, os relatos trazidos explicitavam momentos de alegria e passeios com a filha e com amigos. Sofia estava mais segura, frequentando eventos sociais e brincando com a utilização de uma peruca. Porém confessou sentir-se cansada da rotina de tratamentos. Afirmou que desejava tirar férias assim que terminasse a radioterapia - viajar para outro lugar, onde náo teria hora para acordar. Disse estar precisando mudar de ares, ter desejo de plantar algumas árvores - que representavam a vida brotando nela novamente.

Com o movimento de tornar claro o projeto de ser redefinido por Sofia, ela pôde visualizar situaçóes de felicidade, esperança e saúde. Finalizou o ano com o seguinte discurso:

Esse ano foi ótimo para mim, cresci tanto. Eu tenho certeza de que vou me curar do câncer. Aprendi a não matar tudo no peito, tantas mágoas. 
Aprendi a não culpar tanto os outros, nem a mim mesma. Alimentar mágoas por pessoas que não estenderam a mão pra mim, hoje eu sei que eu devo pedir ajuda, pois hoje eu consigo ver o outro e estender a minha mão também.

Assim, uma vez que Sofia passou a perceber-se no mundo e atuar de modo a buscar maneiras de superar as suas complicaçóes existenciais, articulando as reflexóes aprendidas em psicoterapia na prática do seu cotidiano, o processo de alta pôde ser iniciado.

\section{Consideraçóes finais}

A partir do exposto, considera-se que o câncer, por suas características de etiologia e evoluçáo, bem como pelos tratamentos que demanda, promove alteraçôes na experiência do sujeito, sendo gerador de mudança em sua personalidade. Além disso, o surgimento da doença impele reformulaçóes de seu projeto-de-ser, tendo em vista que sua ocorrência muitas vezes implica em rupturas na história e trajetória que vinha sendo construída até então. Diante destas alterações, é possível que o sujeito se experimente inviabilizado em seu ser e adentre em situações de sofrimento que precisam ser mediadas para serem superadas.

Nestes casos, o trabalho em psicoterapia pode se efetivar na medida em que se conhece a história do sujeito, a história de suas relaçóes e a inteligibilidade que ele direcionou a estas novas ocorrências, experienciadas psicofisicamente. $\mathrm{O}$ objetivo principal do processo torna-se, entáo, o de viabilizar o sujeito a partir destas diferentes condiçôes e horizontes existenciais impostos pela doença, porém sem esquecer que experiências de sofrimento atingem o sujeito em toda sua história e complexidade e não somente naquelas circunscritas à ocorrência do câncer.

No processo psicoterápico desenvolvido com Sofia, a expressão de novos planos indicava que ela, aos poucos, foi redefinindo seu projeto de ser. Até o momento de sua vinda à psicoterapia, por ocasiáo do tratamento do câncer, vivia na espontaneidade, ou seja, sem que tomasse seu eu como objeto de reflexáo, encontrando-se confusa com as novas experiências vividas. A doença inseriu em sua vida novas mediaçóes que a lançaram em uma insegurança ontológica (Laing, 1987), quando passou a sentir dúvidas sobre si mesma, seu futuro, suas açóes e emoçóes. Por meio do processo psicoterápico, foi possível reorganizar seu projeto-de-ser, após ter sido capaz de compreender aspectos importantes da trajetória que havia percorrido e suas possibilidades concretas no presente. 


\section{Referências}

Aguiar, E. N. (2007). A experiência de "súbito" nas ficçôes de Lispector e Sartre. Revista do Departamento de Psicologia-UFF, 19(2), 463-476.

INCA (2009). Estimativa 2010 - Incidência de Câncer no Brasil / Instituto Nacional de Câncer. Rio de Janeiro: INCA - Ministério da Saúde. Recuperado em 12 março, 2012, de <http://www.inca.gov.br/estimativa/2010/>.

Carvalho, M. M. (2002). Psico-oncologia: história, características e desafios. Psicologia USP, 13(1), 151-166.

Chizzotti, A. (2003). Pesquisa em ciências humanas e sociais. São Paulo: Cortez.

Laing, R. D. (1987). O Eu dividido: estudo existencial da sanidade e da loucura. Petrópolis: Vozes.

Maheirie, K. \& Pretto, Z. (2007). O movimento progressivo-regressivo na dialética universal e singular. Revista do Departamento de Psicologia-UFF, 19(2), 455-462.

Neme, C. M. B. \& Lipp, M. E. N. (2010). Estresse psicológico e enfrentamento em mulheres com e sem câncer. Psicologia: Teoria e Pesquisa, 26(3), 475-483.

Peres, R. S. \& Santos, M. A. dos. (2009). Personalidade e câncer de mama: produção científica em Psico-Oncologia. Psicologia: Teoria e Pesquisa, 25(4), 611-620.

Pretto, Z.; Langaro, F. \& Bunn Santos, G. (2009). Psicologia clínica existencialista na atenção básica à saúde. Revista Psicologia Ciência e Profissão, 29(2), 394-405.

Sartre, J.-P. (1997). O ser e o nada. Petrópolis: Vozes (Originalmente publicado em 1943).

Sartre, J.-P. (1978a). O existencialismo é um humanismo. Coleção Os Pensadores. São Paulo: Abril Cultural (Originalmente publicado em 1945).

Sartre, J.-P. (1978b). Questão de método. Coleção Os Pensadores. São Paulo: Abril Cultural (Originalmente publicado em 1960).

Sartre, J.-P. (2006). Esboço para uma teoria das emoçôes. Porto Alegre: L\&PM (Originalmente publicado em 1939).

Schneider, D. R. (2006). Liberdade e dinâmica psicológica em Sartre. Natureza Humana, $8(2), 283-314$.

Schneider, D. R. (2008). O método biográfico em Sartre: contribuiçóes do existencialismo para a Psicologia. Estudos e Pesquisas em Psicologia-UERJ, 8(2), 289-308.

Schneider, D. R. (2011). Sartre a psicologia clinica. Florianópolis: Editora da UFSC.

Silva, L. C. da. (2009). O cuidado na vivência do doente de câncer. Uma compreensáo fenomenológica. Maringá: Eduem.

Sontag, S. (2007). A doença como metáfora \& Aids e suas metáforas. São Paulo: Companhia das Letras.

Van Den Berg, J. H. (1994). O paciente psiquiátrico: esboço de uma psicopatologia fenomenológica. Campinas: Editorial Psy II. 


\section{Nota}

1 Este e outros nomes aqui utilizados são fictícios. Ressalta-se que, na entrevista de triagem, os pacientes atendidos na clínica eram informados sobre as condiçôes de trabalho, incluindo a possível utilização do material dos atendimentos para fins de pesquisa, quando assinavam um termo de consentimento livre e esclarecido.

Recebido em 25 de novembro de 2011 Aceito para publicação em 07 de maio de 2012 